\title{
Forskrivning av prevensjon til unge kvinner
}

\author{
Engelsk oversettelse av hele artikkelen på www.tidsskriftet.no
}

\begin{abstract}
Sammendrag
Bakgrunn. Fra 2002 har spesielt kvalifiserte helsesøstre og jordmødre hatt rekvisisjonsrett for $\mathrm{p}$-piller til kvinner i alderen 16-19 år. Ordningen er senere utvidet til å omfatte all hormonell prevensjon, unntatt hormonspiral. Formålet med denne studien var å evaluere ordningen.
\end{abstract}

Materiale og metode. Reseptregisteret er pseudonomisert og inneholder en rekke karakteristika ved bruker, medikament og forskriver. For denne studien ble det strukturert en database med kvinner født i 1989, totalt 29821 . som enhet for analyse.

Resultater. Henholdsvis $75 \%$ og $79 \%$ av kohorten hadde tatt ut minst én resept på p-piller eller hormonell prevensjon innen utgangen av det kalenderåret de fylte 19 år. Nær $12 \%$ hadde tatt ut minst én resept på minipille, mens langt færre hadde utløst resept for $p$-ring, $p$-sprøyte, $p$-plaster eller hormonspiral. Leger skrev ut to tredeler av reseptene. Helsesøstre skrev ut flere resepter til 17-åringer og 18-åringer enn legene gjorde. Tiden jentene brukte $p$-piller og minipiller var uavhengig av forskriver.

Fortolkning. At nær $80 \%$ av kohorten født i 1989 har tatt ut minst én resept på hormonell prevensjon, viser at det er høy bevissthet om å forebygge uplanlagt svangerskap. Utvidet rekvisisjonsrett til helsesøstre og jordmødre har økt tilgjengeligheten av prevensjon, og unge kvinner benytter seg av tilbudet.
Finn Egil Skjeldestad

eskjelde@online.no

Kvinneklinikken

Avdeling for klinisk medisin

Universitetet i Tromsø

Det foreligger lite kunnskap om prevensjonsbruken hos unge kvinner, da de sjelden er representert i prevensjonsvaneundersøkelser verken i Norge (1-3), de andre nordiske land (4) eller øvrige land i den vestlige verden (4).

Tradisjonelt har kun leger hatt rett til å forskrive prevensjonsmidler. Ett unntak er Sverige, der jordmødre fikk forskrivningsrett ved liberaliseringen av abortloven i 1974. På bakgrunn av erfaringene fra vårt naboland og entydige resultater når det gjelder forebygging av uplanlagte svangerskap fra et prøveprosjekt med tilbud om gratis p-piller på helsestasjoner i 1998-2000 (5) ble gratis p-piller til alle kvinner i alderen 16-19 år innført i Norge fra 1.1. 2002 (6). Fra 1. juni samme år fikk spesielt kvalifiserte helsesøstre og jordmødre rett til å rekvirere prevensjonsmidler, etter særskilt liste fastsatt av Statens legemiddelverk, til kvinner i alderen 16-19 år (6). De første årene omfattet denne retten kun p-piller, men fra februar 2006 ble den utvidet med minipille, prevensjonsring ( $\mathrm{p}$-ring), prevensjonsplaster (p-plaster) og prevensjonssprøyte ( $\mathrm{p}$-sprøyte) (7). Samtidig ble ordningen med gratis p-piller omgjort til fast bidragssats ( $\mathrm{kr}$ 100) over tre måneder til dekning av utgifter til hormonell prevensjon hos unge kvinner (7).

All hormonell prevensjon som subsidieres gjennom bidragssatsordningen er reseptbelagt. Derfor vil Reseptregisteret inneholde alle nødvendige data for individuell utlevering og således være en viktig datakilde for evaluering av ulike sider ved statens satsing på større tilgjengelighet av hormonell prevensjon til unge kvinner. Formålet med denne studien var, ut fra brukermønster og forskrivers profesjon, å evaluere prevensjonsbruken i en kohort av unge kvinner som har benyttet seg av tilbudet om gratis prevensjon/fast bidragssats.

\section{Materiale og metode}

Landets apoteker har registrert resepter elektronisk i mange år. Fra 1.1. 2004 er disse opplysningene overført til Reseptregisteret etter at personidentifiserbare data om legemiddelbruker og forskriver (helsepersonell) er pseudonymisert (8). Pseudonym for legemiddelbruker og forskriver er personentydig, slik at legemiddelforbruket kan følges over tid for både bruker og forskriver.

Med reseptuttak som enhet for registrering inngår følgende opplysninger om legemiddelbrukeren: pseudonym (løpenummer), fødselsår, fødselsmåned, kjønn og bostedskommune. For legemidlet er det data om: anatomisk-terapeutisk legemiddelkode (ATCkode), varenummer, antall pakninger, refusjonspunkt, dato for uthenting osv. Data om forskriveren er: pseudonym (løpenummer), fødselsår, kjønn, profesjon, spesialitet, i tillegg er det opplysninger om apotek.

Fra 1.1. 2004 til 31.12. 2008 ble det registrert 4729890 reseptuttak som gjaldt hormonelle prevensjonsmidler (ATC-kode G03A) i Reseptregisteret. Etter eksklusjon av uttak til menn ( $\mathrm{n}=779)$, nødprevensjon (Norlevo, Postinor; $n=1131$ ), prosjektrelaterte $p$-piller $(\mathrm{n}=568)$, utenlandske statsborgere/ufullstendig personidentitet $(n=200237)$ og opplagte feil i fødselsår $(n=416)$ omfattet data i registeret 4526759 reseptuttak for hormonell antikonsepsjon for kvinner i alderen 10-59 år. Fra dette materialet ble det identifisert 216528 uttak hos 23502 kvinner født i 1989.

Denne 1989-kohorten ble 15 år i løpet av første virkeår for Reseptregisteret i $2004 \mathrm{og}$ 19 år i løpet av 2008. Kohorten omfattet 29821 unge kvinner per 31.12. 2008 (9). Dette utgjør studiepopulasjonen.

Antallet resepter for hormonell antikonsepsjon per kvinne født i 1989 varierte fra 0 til 61 frem til utgangen av kalenderåret de fylte 19 år. Data ble først sortert etter dato for reseptuttak. Uttak av flere resepter på samme preparat på samme dato ble programmert til ett uttak, der antall døgndoser ble summert. Pakningsstørrelsen anga antall utleverte døgndoser. Virketid for én injek-

\section{Hovedbudskap}

- $79 \%$ av kvinnene i vår studie tok ut resept på hormonell prevensjon innen utgangen av det året de fylte 19 år

- Leger står for to tredeler av foreskrivningen av hormonell prevensjon til jenter $\mathrm{i}$ aldersgruppen 16-19 år

- For jenter i alderen 17-18 år er helsesøster dominerende forskriver

- Helsesøstrene er blitt betydningsfulle prevensjonsveiledere for unge kvinner 
sjon av prevensjonssprøyte (p-sprøyte) ble satt til 90 dager, for implantatene Implanon og Jadelle til henholdsvis 1080 og 1800 dager, likeledes ble hormonspiralens virketid satt til 1800 dager.

Brukertiden ble definert ved kontinuerlige uttak av samme type prevensjon fra dato for første uttak til dato (pluss antall døgndoser) ved siste uttak. Kontinuerlige uttak ble definert som uttak der oppholdet mellom angitte døgndoser og neste uttak var under 60 dager. Ved skifte av prevensjon ble brukertiden beregnet som dato fra uttak av for eksempel p-piller til dato for uttak fra apoteket av vaginalring (p-ring), selv om antall uttatte døgndoser for $\mathrm{p}$-piller ikke var brukt opp. Tilsvarende ble brukertiden av for eksempel hormonspiral/implantater redusert ved overgang til p-piller eller andre hormonelle prevensjonsmidler før virketiden av tidligere uttak var utløpt justert til uttaksdato av det nye prevensjonsmidlet.

I Reseptregisteret er helsepersonell registrert som lege, helsesøster, jordmor, tannlege og veterinær. Pseudonym for lege kobles til Helsepersonellregisteret, hvor det er opplysninger om utdanningsår, år og type spesialitet/subspesialitet. Der en lege har flere spesialiteter/subspesialiteter, er sist registrerte spesialområde definert som legekategori. Leger som ikke har spesialistkompetanse, er definert som under spesialisering. Med utgangspunkt $\mathrm{i}$ formålet for studien ble leger klassifisert som under spesialisering, spesialist i allmennmedisin/samfunnsmedisin, spesialist $i$ indremedisin, spesialist $i$ kirurgi, spesialist i fødselshjelp og kvinnesykdommer og som annen type spesialist. Seks resepter fra tannleger og veterinærer ble ekskludert fra videre analyser.

Alle analyser ble gjort i Statistical Package for Social Sciences (SPPS) versjon 17 overlevelsesanalyser, med signifikansnivå $\mathrm{p}<0,05$.

\section{Resultater}

Totalt hadde 23502 av 29821 (78,9\%) kohorten kvinner født i 1989 - tatt ut minst én resept på hormonell antikonsepsjon før eller i det kalenderåret de fylte 19 år. De aller fleste $(<75 \%)$ hadde tatt ut minst én resept på p-piller. I mindre grad var det tatt ut resept på minipiller $(<12 \%)$, p-sprøyte $(<5 \%)$, p-plaster $(<4 \%)$, p-ring $(<3 \%)$, implantater $(<2 \%)$ og hormonspiral $(<1 \%)$. Flest førstegangsresepter skrives ut til jenter i 16-17-årsalderen (tab 1). I det kalenderåret de fylte 15 år, tok $9 \%$ av kohorten ut minst én resept på prevensjon, først og fremst gjaldt det p-piller $(8,2 \%)$ (tab 1).

To tredeler av alle førstegangsresepter for hormonell prevensjon skrives ut av lege, nær en tredel skrives altså ut av helsesøster. Av medisinerne er leger under spesialisering og spesialister i allmennmedisin/samfunnsmedisin de hyppigste forskriverne. Spesia- lister i fødselshjelp og kvinnesykdommer skriver ut få resepter til kvinner i denne aldersgruppen, på nivå med det jordmødre gjør (tab 2).

P-piller til 15-åringer skrives ut av leger (tab 3). For jenter i overgangen til og i videregående skole er det helsesøster som forskriver flest resepter på p-piller. Andelen førstegangsresepter skrevet ut av spesialist i fødselshjelp og kvinnesykdommer, andre legespesialister eller jordmor er lav på alle alderstrinnene 15-19 år (tab 3).

$\mathrm{Ni}$ av ti bruker p-piller kontinuerlig i lengre tid etter oppstart. Første episode av p-pillebruk varte i gjennomsnitt 21-22 måneder (variasjon 0-60 md.), og det var ingen forskjell etter forskriver (overlevelsesanalyser)-helsesøster 21,4 måneder (variasjon 0-60 md.), lege under spesialisering 21,4 måneder (variasjon 0-60 md.), spesialist i allmennmedisin/samfunnsmedisin 22,8 måneder (variasjon 0-60 md.). Gjennomsnittlig brukertid for første resept av de andre prevensjonsmidlene varierte: p-sprøyte 17 måneder, minipille og implantater 13 måneder (variasjon $0-59 \mathrm{md} . \mathrm{og}$ 0-51 md.), p-plaster 11 måneder (variasjon 0-59 md.), p-ring ti måneder (variasjon 0-59 md.) og hormonspiral ti måneder (variasjon 0-51 md.).

Etter å ha ekskludert de kvinnene som hadde brukt/brukte hormonspiral $(\mathrm{n}=130)$ og implantat $(\mathrm{n}=456)$, viste det seg at $6 \%$ av de gjenværende hadde tatt ut prevensjon

Tabell 1 Alder ved innløsning av første resept etter type hormonell antikonsepsjon og kumulativ andel som har innløst resept totalt. Analysene omfatter hele kohorten

Type hormonell prevensjon

\begin{tabular}{|c|c|c|c|c|c|c|c|c|}
\hline Alder (år) & $\begin{array}{l}\text { P-piller } \\
(\%)\end{array}$ & $\begin{array}{c}\text { P-plaster } \\
(\%)\end{array}$ & $\begin{array}{c}\text { P-ring } \\
{[\%]}\end{array}$ & $\begin{array}{c}\text { P-sprøyte } \\
(\%)\end{array}$ & $\begin{array}{l}\text { Minipille } \\
{[\%]}\end{array}$ & $\begin{array}{l}\text { Implantater } \\
{[\%]}\end{array}$ & $\begin{array}{c}\text { Hormonspiral } \\
(\%)\end{array}$ & $\begin{array}{l}\text { Total kumulativ andel } \\
\qquad \%]\end{array}$ \\
\hline 15 & 8,2 & 0,3 & 0 & 0,5 & 0,2 & 0 & 0 & 9,0 \\
\hline 16 & 23,8 & 0,4 & 0,1 & 0,7 & 1,3 & 0,1 & 0 & 33,7 \\
\hline 17 & 22,0 & 0,8 & 0,4 & 1,3 & 2,7 & 0,3 & 0,1 & 56,5 \\
\hline 18 & 12,9 & 1,1 & 1,0 & 1,1 & 3,9 & 0,5 & 0,1 & 70,3 \\
\hline 19 & 7,8 & 1,2 & 1,3 & 1,0 & 3,7 & 0,6 & 0,3 & 78,9 \\
\hline $15-19$ & 74,7 & 3,8 & 2,8 & 4,6 & 11,8 & 1,5 & 0,5 & 78,9 \\
\hline
\end{tabular}

Tabell 2 Forskriver av første resept etter type hormonell prevensjon. Analysene omfatter hele kohorten

\begin{tabular}{|c|c|c|c|c|c|c|c|c|}
\hline \multirow[b]{2}{*}{ Forskriver } & \multicolumn{8}{|c|}{ Type hormonell prevensjon } \\
\hline & $\begin{array}{c}\text { P-piller } \\
(\%)\end{array}$ & $\begin{array}{c}\text { P-plaster } \\
{[\%]}\end{array}$ & $\begin{array}{l}\text { P-ring } \\
(\%)\end{array}$ & $\begin{array}{c}\text { P-sprøyte } \\
(\%)\end{array}$ & $\begin{array}{c}\text { Minipille } \\
{[\%]}\end{array}$ & $\begin{array}{c}\text { Implantater } \\
(\%)\end{array}$ & $\begin{array}{c}\text { Hormospiral } \\
{[\%]}\end{array}$ & $\begin{array}{c}\text { Totalt } \\
(\%)\end{array}$ \\
\hline Leger under spesialisering & 20,1 & 1,3 & 0,9 & 1,9 & 4,1 & 0,8 & 0,2 & 22,5 \\
\hline Spesialist i allmennmedisin/samfunnsmedisin & 17,2 & 1,0 & 0,5 & 1,6 & 3,7 & 0,4 & 0,2 & 18,9 \\
\hline Spesialist i indremedisin & 0,6 & 0 & & & 0,1 & & & 0,7 \\
\hline Spesialist i kirurgi & 0 & & & & 0,01 & & & 0 \\
\hline Spesialist i fødselshjelp og kvinnesykdommer & 1,6 & 0,1 & 0,3 & 0,2 & 0,4 & 0,2 & 0,1 & 1,8 \\
\hline Andre legespesialister & 2,7 & 0,1 & 0,1 & 0,2 & 0,6 & 0,1 & & 3,0 \\
\hline Helsesøster & 30,4 & 1,1 & 1,0 & 0,6 & 2,7 & & & 31,6 \\
\hline Jordmor & 2,0 & 0,1 & & 0,1 & 0,2 & & & 2,0 \\
\hline Ingen forskrivning & 25,3 & 96,2 & 97,2 & 95,4 & 88,2 & 98,5 & 99,5 & 21,1 \\
\hline
\end{tabular}


Tabell 3 Andel førstegangsresepter for p-piller forskrevet til jenter på ulike alderstrinn og totalt etter forskrivers profesjon. Analysene omfatter hele kohorten

\begin{tabular}{|c|c|c|c|c|c|c|c|}
\hline \multirow[b]{2}{*}{$\begin{array}{l}\text { Brukers } \\
\text { alder (år) }\end{array}$} & \multicolumn{7}{|c|}{ Forskriver av p-piller } \\
\hline & $\begin{array}{c}\text { Leger under } \\
\text { spesialisering } \\
\text { (\%) }\end{array}$ & $\begin{array}{c}\text { Spesialist i allmenn- } \\
\text { medisin/samfunnsmedisin } \\
\text { (\%) }\end{array}$ & $\begin{array}{c}\text { Spesialist i fødselshjelp } \\
\text { og kvinnesykdommer } \\
(\%)\end{array}$ & $\begin{array}{l}\text { Andre lege- } \\
\text { spesialister } \\
\text { (\%) }\end{array}$ & $\begin{array}{c}\text { Helsesøster } \\
(\%)\end{array}$ & $\begin{array}{c}\text { Jordmor } \\
{[\%]}\end{array}$ & $\begin{array}{c}\text { Andel } \\
\text { av kohorten } \\
(\%)\end{array}$ \\
\hline 15 & 3,6 & 3,5 & 0,3 & 0,8 & 0,1 & 0 & 8,2 \\
\hline 16 & 6,9 & 5,9 & 0,3 & 1,1 & 9,0 & 0,6 & 23,8 \\
\hline 17 & 4,1 & 3,4 & 0,4 & 0,6 & 12,7 & 0,8 & 22,0 \\
\hline 18 & 3,1 & 2,6 & 0,4 & 0,4 & 6,0 & 0,4 & 12,9 \\
\hline 19 & 2,4 & 1,9 & 0,3 & 0,5 & 2,7 & 0,2 & 7,8 \\
\hline $15-19$ & 2,1 & 17,2 & 1,6 & 3,4 & 30,4 & 2,0 & 74,7 \\
\hline
\end{tabular}

for seks måneder lenger enn hva de maksimalt kunne ha brukt fra første resept til sensurering 1.1.2009.

Bidragssatsen gjelder tre måneders bruk. Dette gjenspeiles i at 96-97\% av kvinnene løste inn resept (p-piller, minipiller, p-ring, p-plaster, p-sprøyte) for kun tre måneder om gangen.

\section{Diskusjon}

Bevisstheten om bruk av prevensjon er høy, da nær $80 \%$ av hele fødselskohorten hadde løst inn minst én resept på hormonell prevensjon før de hadde fylt 20 år. Tre firedeler av kohorten hadde brukt p-piller og nær $12 \%$ minipiller. De øvrige administrasjonsformene av hormonell prevensjon er nyttige alternativer, men brukes av få (tab 1). Studien omfatter ikke kobberspiralbruk, men vi antar at bruken av slik spiral i denne aldersgruppen er liten, på størrelse med hormonspiralbruken. Derfor vil manglende opplysninger om bruk av kobberspiral i svært liten grad påvirke resultatene.

Mønsteret for forskrivning av første resept var det samme for alle alderstrinn fra 15 år til 19 år og rimelig konstant for de ulike profesjonene (tab 1, tab 3). Det forskrives langt mer p-piller enn de øvrige hormonelle prevensjonsmidlene.

Helsesøstre/jordmødre har kun forskrivningsrett til kvinner over 16 år, og studien viser at kun $0,1 \%$ av kohorten hadde fått forskrevet p-piller av helsesøster/jordmor før de hadde nådd 16 års alder. I studien var alder estimert som forskjellen mellom år for innløsning av første resept og fødselsår. Det kan i noen tilfeller være for unøyaktig, men det er liten grunn til å tro at dette representerer et problem $i$ henhold til forskriften.

Det er først og fremst leger under spesialisering, spesialister i allmennmedisin/samfunnsmedisin og helsesøstre som forskriver p-piller og annen hormonell prevensjon til unge kvinner. Andre legespesialiteter og jordmødre forskriver i liten grad hormonell prevensjon.

Helsesøstre forskriver mer p-piller (tab 3) og minipiller (data ikke visst) enn leger til jenter på 17 år og 18 år. For disse er helse- søster lett tilgjengelig både ved helsestasjon for ungdom og i skolehelsetjenesten.

Det at nesten alle (96-97\%) innløste resepter for kun tre måneder ved apoteket, viser at tilskuddsordningen har betydning for hvordan unge kvinner bruker hormonell prevensjon. Det kan i noen tilfeller bety opphold i prevensjonsbruken om man ikke er påpasselig med å innløse ny resept $\mathrm{i}$ tide, men for de fleste er ikke dette noe problem. Noen brukere innløste samme resept samme dag eller med få dagers mellomrom. I studien er det ikke gjort forsøk på å finne ut om disse brukerne opererte med forskjellige resepter eller om de brukte samme resept ved forskjellige apoteker.

Det at $6 \%$ av kohorten hadde løst inn resepter tilsvarende døgndoser for bruk mer enn seks måneder utover hva de selv kunne klare å bruke i tidsperioden for studien, kan ha med bivirkninger/skifte mellom forskjellige administrasjonsformer av hormonell prevensjon å gjøre, eller det kan skyldes utenlandsreiser der man tar med seg prevensjon for en lengre periode. Men man kan heller ikke se bort fra at venninner hjelper hverandre i perioder hvor en mangler prevensjon eller har mistet/forlagt aktuelle prevensjon. Det vil være uheldig om noen tar ut p-piller til venninner som ikke burde bruke dette på grunn av kontraindikasjoner eller er blitt frarådet av lege/helsesøster.

Gjennom litteratursøk er det ikke funnet liknende studier der man har analysert prevensjonsbruk etter forskrivers profesjon. Dette lar seg heller ikke gjøre i det danske reseptregisteret, der opplysninger om forskriver mangler (10).

Helsesøstre er blitt betydningsfulle prevensjonsforskrivere til unge kvinner. Intensjonene $\mathrm{i}$ forskrift om fast bidragssats til hormonell prevensjon følges. Til jenter under 16 år skriver helsesøstre/jordmødre nærmest ikke ut hormonell prevensjon, men til jenter i alderen 17-18 år er helsesøster dominerende forskriver fordi hun er lett tilgjengelig. Leger under spesialisering, spesialister $\mathrm{i}$ allmennmedisin/samfunnsmedisin og helsesøstre står for det meste av forskrivningen av prevensjon til unge kvinner i alderen 15-19 år.

\section{Finn Egil Skjeldestad (f. 1950)}

er ph.d. og professor i gynekologi og obstetrikk ved Forskningsgruppe Kvinnehelse og perinatalogi, Institutt for klinisk medisin, Det helsevitenskapelige fakultet, Universitetet i Troms $\varnothing$. Han har lang forskningserfaring innenfor reproduksjonsepidemiologi og har blant annet publisert flere prevensjonsvaneunders $\varnothing$ kelser fra Norge.

Ingen oppgitte interessekonflikter.

\section{Litteratur}

. Østby L. Prevensjonsbruken i Norge. Tidsskr Nor Lægeforen 1983; 103: 1793-7.

2. Skjeldestad FE. Choice of contraceptive modality by women in Norway. Acta Obstet Gynecol Scand 1994; 73: 48-52.

3. Skjeldestad FE. Prevensjonsbruken i Norge i 2005 Tidsskr Nor Lægeforen 2007; 127: 2803-5.

4. Skouby SO. Contraceptive use and behavior in the 21 st century: a comprehensive study across five European countries. Eur J Contracept Reprod Health Care 2004; 9: 57-68

5. Skjeldestad FE. Forsøk med samlivs- og prevensjonsveiledning i kommuner 1997-2000. Trondheim: SINTEF Helse, 2001

6. Forebygging av uønsket svangerskap og abort. Retningslinjer for helsesøstres og jordmødres rett til å rekvirere prevensjonsmidler til unge kvinner i alderen 16 til og med 19 år. Rundskriv |-3/2002. Oslo: Helsedepartementet, 2002

7. Forebygging av uønsket svangerskap og abort blant tenåringer. Innføring av fast bidragssats for dekning av utgifter til hormonell prevensjon til unge kvinner $\mathrm{i}$ alderen 16 til og med 19 år. Rundskriv I-1/2006. Oslo: Helse- og omsorgsdepartementet, 2006

8. Furu K. Establishment of the nationwide Norwegian Prescription Database (NorPD) - new opportunities for research in pharmacoepidemiology in Norway. Norsk Epidemiologi 2008; 18: 129-36.

9. Statistisk sentralbyrå. Befolkning/tabell: 05839: Folkemengde, etter kjønn og ettårig alder. http://statbank.ssb.no/statistikkbanken/. Emne: 02 (3.11.2011)

10. Danish Medicines Agency (Lægemiddelstyrelsen). http://laegemiddelstyrelsen.dk/en/topics/ statistics,-prices-and-reimbursement/ statistics-and-analyses/ (3.11.2011).

Mottatt 23.5. 2011, første revisjon innsendt 16.9. 2011, godkjent 3.11. 2011. Medisinsk redaktør Jon Amund Kyte. 